\title{
The Exterior Design of Books for the Visually Impaired
}

\author{
Yuchuan Guo ${ }^{1}$, Yuanyuan Fan ${ }^{2}$ \\ ${ }^{1}$ University of jingdezhen ceramic art institute of design, China;333403 \\ ${ }^{2}$ Tsinghua university academy of fine arts, China; 100084
}

Keywords: Books for visually impaired Exterior Features Design

\begin{abstract}
This paper will present the importance of the exterior design of books based on the needs of the visually impaired population. Based on the theories of book design, this paper will discuss about whether there is a need to focus on the exterior design of such books in real life and how to realize such design in order to achieve the consistency between the content and exterior form of such books. Meanwhile, this paper is expected to promote the study of book design for the disadvantaged.

Books as a carrier of information transmission, more and more people become an indispensable part of daily life, especially in today's information age, there are plenty of books appear in front of us, concept books, electronic books, audio books, jumped out to challenge the traditional paper books, and so on from a technical means and different forms, special material and technology development trend to reflect the diversity of the books, in order to reveal the present rich and colorful art books, embodies the aesthetic and the pursuit of the vast number of people in this world. Usually, people in choosing a book is often decided by external form its purchase, collection, this also led to ignore the integrity of the internal structure of books, we can see from this form for the role of books in the ideology of people occupy the main determinants, and guides people's subjective judgment, and the understanding and evaluation of book design just stay on the pattern of beauty in appearance, and people also see to promote these new books to the form of excessive attention, so the content and form of relationship seems to be in a vague definition. Mr Lu jingren referred to in the "calligraphic art asks:" books design is a kind of "tectonics" is to build the external books formative physical ideas and rational thinking on the inner information of comprehensive knowledge, after the designer accurately grasp the content would then understanding of the subject from perceptual initiation, savvy and intellectual and overall, and after careful calculation, elaborate structure and logistically of rhythm and process steps such as organized and orderly construct designers' construct '" in the heart. Books design, therefore, is to build a whole structure, the concept of form a complete books are supposed to be external modelling of the structure of the building as well as the internal thoughts of emotional rendering, both through the analysis of rational conveys the connotation of books, finally to achieve the perfect fusion of books to read aesthetic and function, so that the content and form, art and function to achieve unification 。

So many books as designers started to explore in the field of theory and practice of these problems, will rise to the definition of the overall book design level, no longer the superficial appearance, to interpret the concept of overall structure, contents and forms of the dialectical relationship between the theory and practice together throughout the entire process of design, the design theory of "functional" seems to play the biggest role here, lead the books design changes, thus in the great majority of the population of concern books design should not only have the beautiful external form, have coordinated with the internal emotional thought, the content of the book to the external form, the unity of form and content reflect the beauty of the books of the whole and the overall design concept of the trinity。
\end{abstract}

\section{The analysis of the external form books for the blind}

Through the above you can see people in one area of the conclusions are often represent the idea and concept of the vast number of people, in the form of design also embodies the spiritual pursuit of these groups, and focusing on the edge of the crowd is almost in a pocket, seemed to have failed 
to embody humanistic care, also failed to fully consider the meaning of the design from the starting point of social vulnerable groups, we know the attention to vulnerable groups only from the Angle of the product design to improve the People's Daily behavior, from the environmental facilities are modified to reflect the care of human nature, but if put vision in the books to find books for the blind in the field of design research is still in a relatively blank stage, in access to relevant data also found little about this part of the literature, the discussion of some content in addition to put forward in the construction of the library reflects the care of vulnerable groups, there is no other, more failed to put forward in the books design change; In the literature reading, only a dissertation discusses communication form is a special group of books, through the guidance of tactile graphics reading, also did not establish the comprehensive thinking space, other articles to explore innovation model from the perspective of service design, almost did not read books the overall design concept for the blind. If we emphasize that the above books design the dialectical unification of content and form of entirety, the blind man's books just stay on the use of the function, design form tactile decides the help of books, the most basic reading function, achieve access to information through touch, and the external form in a relatively ignored position, if from the perspective of book design is almost with no form, thus inspired an Angle to think, books for the blind need external form, become a controversial problem, even a marginal problem. Therefore, I hope that through this paper puts forward such a question: when now paper books still dominate, books design in the form of embodiment of the overall concept of the trinity at the same time, the external form of the books for the blind need do not need to design, if you need to how to reflect the dialectical unity of content and form? Design the concept of "tectonics" books, can be more widely to interpret o

We know that the decision of the books should be has the beauty of external form of formal beauty and pleasing to the eye, the internal structure reflect the content of the book, grasp the books of the combination of the overall structure, from such a relationship to look at books for the blind, the overall concept of lack the most basic. Throughout the books for the blind in the external morphological structure, look from materials and technology, the traditional paper-based materials bearing blind spots, achieve information read by touching the bulge, kraft paper, paper adopt to ensure that the reading is not easy to damage. At the same time, the categories of books does not divide, printing process, in the form of did not reflect, therefore also does not have the distinction of hardcover and paperback; From the design pattern, USES the magnanimous folios, the form reflect basic read function, graphics and text to dot structure to meet the requirements of the touch reading, because books have a larger size, and has certain thickness, so the binding mode is given priority to with plastic loaded and locking wire. Due to the lack of books classification also contributed to the design form of simplification, the overall form of books slightly rough, given the heavy depression in heavy form. (figure 1)

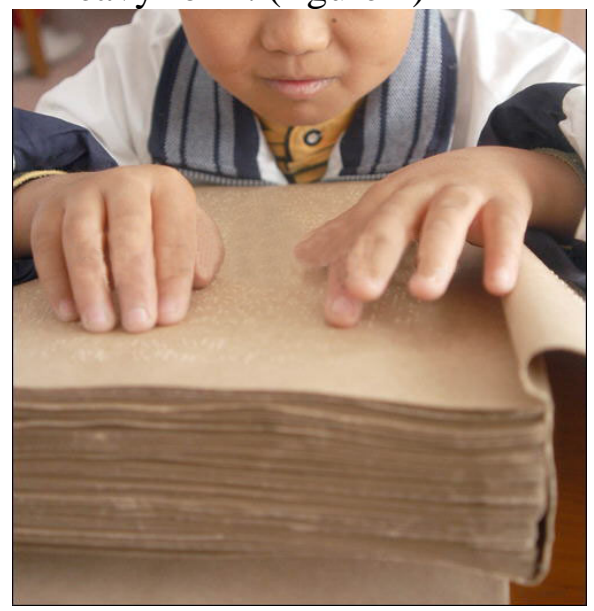

(figure 1) 


\section{The necessity of external form design books for the blind}

From the perspective of the analysis of the above, the blind books lack of the external form, its design is black and white, there is no characteristic, marginalized, even there is no beauty of the most basic concepts, such books shape with simple book conveys a concept: the blind have a visual impairment, books don't need to design the external form, as long as can achieve reading. Analysis from these aspects, the writer conducted investigation and interview, when asked about the problem, you get the answer, here in the following several aspects to elaborate the necessity, design of books for the blind external form the hope can have the effect of topic, books design research further attention to vulnerable groups, to achieve a better solution, realize the design of humanistic care 。

1 , because of neglect of the vulnerable group, and that in many ways we can see their awkward position, the key is the vast number of people are not set up the attention to vulnerable groups, blind books from the library data put also see the same books for the blind and the differences between those books with the formal beauty, it embodies the disregard of social vulnerable groups on the one hand, on the other hand, the relationship of the people seem to have the slit, the resulting distance and therefore more and more strange, therefore, give the blind books in certain external form, here, from the perspective of humanistic care to reflect the form of the design to raise the vast number of groups concerned about the disadvantaged groups. Humanistic care, from the western humanism tradition, its core lies in the human nature, certainly emphasizes the human dignity and value, respect the person's main body status and individual differences. To the blind of the humanistic care embodied in many aspects of caring, multi-level needs, need not only care about the physical level, more concerned about the spiritual and cultural level of people. Books are the carrier of knowledge, but also the emotional way of communication, based on the aesthetic and cultural level of book design more need for vulnerable groups to establish emotional communication, they also have the most basic design requirements, with inner emotional appeal. In addition, when we are faced with a variety of books for the blind, can also be deeply realized that a book designer care of vulnerable groups, citizen moral ideas here fully embodied in the smallest part of the people as the main body plays a role fully, also reflected the books for the blind emotion euphoric 。

2 , from the point of view of design, the integral design of the books for the blind lack even the most basic concept, although the books for the blind internal structure is simple, the form to reflect the text and graphics, but for the importance of the external form is not only embodied humanistic care, more is reflected by the sense of touch books material beauty, from inner emotional arousal realize external form. We know different material gives a person the sense of touch feeling is not the same, the material itself does not represent feelings, only when in contact with it can embody its emotion, the beauty of books material can touch interact with books, convey the beautiful feeling. Interaction, here reflects the relationship between the people and things, the interaction is not the interaction between human and machine, but the emotional exchange between the people and things, the simple sense of material convey touch produces psychological touches with people, and in the process of conveying information to produce emotional resonance. So to special populations, such as the blind more need to use good material to reflect the quality of books, to induce them to imagine, browse through the books overall shape of the fun of reading, and then realize the pleasure of beauty. In the external form of books for the blind, a controversial is how to design, how to design problems, follow the principle of books design content and form, the blind books also need according to the content to determine the external form, reflect the law of formal beauty, avoid books with ordinary fracture phenomenon. In the process of design, through the graphics and text books for the blind in the external form, color and material appropriate indicators of the overall structure of the books, graphics and text book shall be transmitted by the basic point of convex, certain arrangements and the external form of the polychromy books adopted according to the categories of books has the texture of the material for special groups in the process of touch feelings of beauty, material binding way according to the thickness of the book and content to determine the whole book, jacket, jackets, ribbon, bookmarks, etc as the content of the external design is attached 
to the whole plan, follow the principle of holistic design of book design. The beauty of the books, therefore, not only represents the aesthetic needs of the vast number of people, also gives special groups the most special care, design here fully embodies the human nature is the most beautiful part, also convey the books design special form of language. (figure 2, 3, 4, 5)

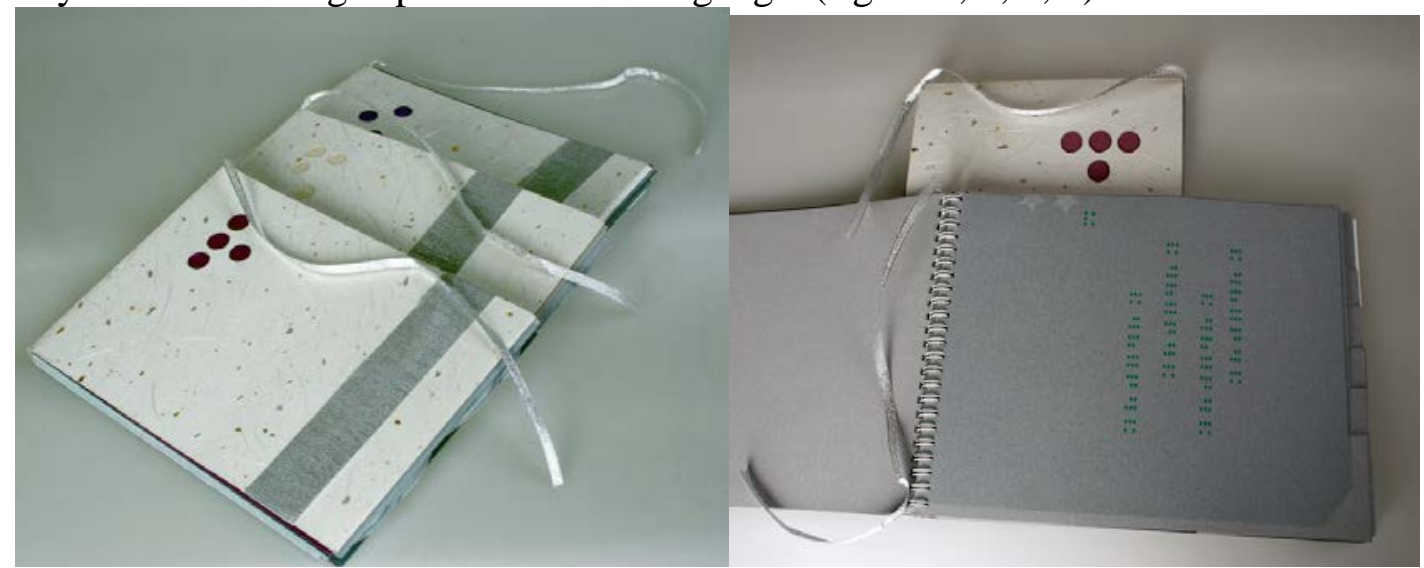

figure 2

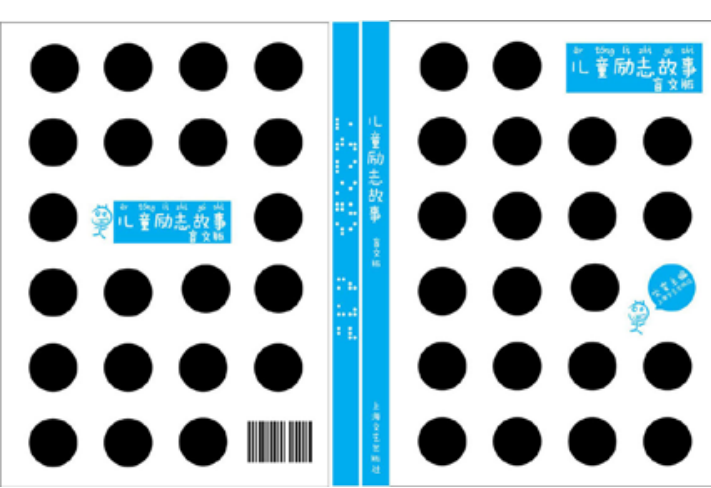

figure 4

figure 3

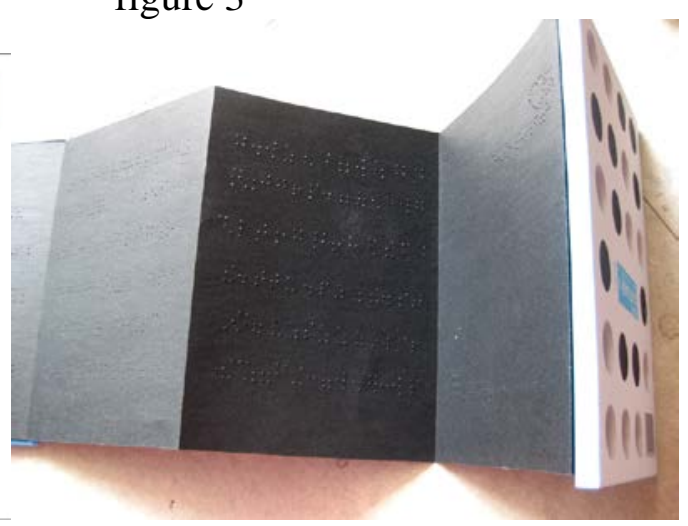

3 , in the current research in the field of design books, books for the blind has more potential research value as part of the marginalized, especially for the external form of controversy still have different opinions and propositions. Research status at home and abroad are rarely involved in the design and study of books for the blind, the blank need more books in the field of stylist to undertake the study of theory and practice of inspection, at the same time, in the aspect of development trend of design will lead the blind books books design new development direction, from the perspective of more comprehensive and disciplines to explore this part of the design requirements of the special groups, such as involved in the design values on the one hand, li-xin referred to in the "design value" : "in the design, the new core values should be reflected in whether has the design integration, namely in the design of structural elements inside and outside of coordination, convergence or coexist in various design ideas, creativity is the main body of men to make things more hasten is perfect, eventually make the person's harmony, harmonious social life." So, inside and outside the structure of the books for the blind design coordination is embodied in the lack of external form, the value of the corresponding system is difficult to set up systematic, therefore, to construct the blind books design is not only reflected in the value system of a person's behavior and concept and design, but need more people to establish such a value idea to apply the books design to construct the core value in the overall design of books for the blind, people as the main body of creation activity, ought to make the design of purpose, meaningful, valuable, to establish the value of the books for the blind design system has become necessary 。

Through the three aspects of books for the blind in external form, visible in the form of external design plays a crucial role, seize the external form of this view point to analyze the blind books the whole and partial structure relations, is the books design have been discussed. If books design is regarded as a large system, and books for the blind can not be ignored, it reflects the design of the humanistic care, the subject status of the people's value is a reflection of the design values, a 
comprehensive interpretation of the design, the concept of service for all the masses, and jointly create a harmonious society。

\section{Conclusion}

Books carry the form of beauty, convey the beautiful feeling and experience, the form of paper books has kept its unique and irreplaceable reading experience, braille books for blind people, is the source of knowledge, is touching the window of the world, it also requires the external morphological characteristics of the books for the blind in this kind of special crowd outside the basic physiological needs, we still need to give it the beautiful shape, this is not only arouse the vast number of groups of care and attention to special people, more is the return of the emotion and communication. Nots allow to ignore, books for the blind is still faced with crisis of marginalization, some problems still need more books designers through the combination of theory and practice to explain the blind books overall design concept, design of its external form dispute also reflects only a small part of the problem, we need to define the overall concept of books for the blind design, also need to build such a concept to books, beauty of art form。

\section{References}

[1] XiaoQian "principle of dialectical materialism", Beijing: people's publishing house, 1991.09

[2] Wu Xiang design morphology, chongqing: chongqing university press, 2008

[3] lu jingren the calligraphic art asked], Beijing: China youth press, 2006.10

[4] li-xin "design value", Beijing: China building industry press, 2011.9

[5] Susan (beauty). Long "emotion and form", Beijing: China social sciences press, 1986.8

[6] British) block "the western humanism tradition", Beijing: QunYan press, 2012.4

[7] (the) victor his Nike "designed for the real world", Beijing: zhongxin press, 2013.1 